\title{
Ergonomic assessment of porridge roaming sale system
}

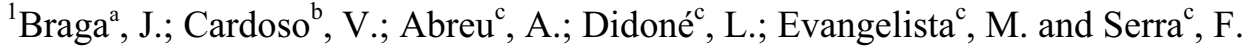 \\ Ergonomics Research and Development Center, Federal University of Amazonas, Av. General Rodrigo Otávio, $n^{\circ}$ \\ 3.000, Aleixo, CEP 69.077-000, Manaus- AM, Brazil
}

\begin{abstract}
This paper makes suggestions for the realization of an ergonomic intervention, guided by the method of Moraes and Mont'Alvão (2009), in the system of street vending of porridge, to improve the working conditions of this sales segment. Specifics are given about this practice and its problems, from ergonomic analysis comes to suggestions for improvements to be applied to a new system.
\end{abstract}

Keywords: postural constraints, cargo handling, hawker, ergonomic suggestions, improvements.

\section{Introduction}

The custom of eat porridge is embedded in the culture of the Amazonas state. For this reason this food vendors, who usually are hawkers, are present in various places of the capital and interior of the state, where street vending of porridge is made in poor conditions that can favor the spread of diseases. Besides the lack of hygiene, many factors are responsible for the poor working condition of these vendors, and one of the main constraints that cause discomfort and injury is poor posture. Iida [4] states that poor posture can cause generalized muscle fatigue, pain, blood circulation complications - which can cause varicose veins - and musculoskeletal disorders.

The main activities conducted by these professionals involve transportation and sale of porridge in small improvised vehicles of one or two wheels and wanderings in these activities that generate a sequence of overload on the spine.

According to Chaffin [2], researches indicate that there is a significant increase in musculoskeletal disorders and onset of fatigue with the variation of the following factors: load, volume, position, frequency and duration of activity. Thus, the long distances traveled, the excess weight in the cart and weathering, are just some of the problems faced daily by the worker.

According to Moraes and Mont'Alvão [6], to increase productivity and quality must be improved working conditions. Therefore, suggestions are made in order to alleviate problems related to the constraints and human costs observed, seeking to improve the performance of these workers.

\section{Delimitation of the problem and taxonomic classification}

\subsection{Delimitation of the problem}

The mobile sales of porridge, due to poor conditions in which it occurs, causes numerous problems and the seller ends up making this drudgery. Long distances are covered for the sale is made and the expedient is only complete when all the product is sold as the same cannot be stored to be sold the next day. Is worth remembering that any time a worker is

\footnotetext{
1 a Graduating Design, Federal University of Amazonas and Member of Ergonomics Research and Development Center , e-mail: bragajuan@hotmail.com; ${ }^{\mathrm{b}}$ MSc. Professor at Federal University of Amazonas and Head of Ergonomics Research and Development Center; ${ }^{c}$ Graduating Design, Federal University of Amazonas
}

$1051-9815 / 12 / \$ 27.50$ (C) 2012 - IOS Press and the authors. All rights reserved 
subject to the inclemency because of the inexistence of an adequate system to protect it (Figure 1), which can cause sunburn, skin diseases or the loss of your goods because of rain abrupt (common at certain times of year).

It is very important to consider how the user moves the load you carry and in the case of the porridge seller, this movement is by means of a wheelbarrow (small car equipped with one front wheel and two rears) which is adapted to sales activity of porridge, but its true function is to transport construction materials over short distances. The frequent use of this type of transport causes back pain, acquired because of the postures assumed during use and the weight of the load that easily exceeds the safety limits for the work to be done without being put at risk the health of the column.

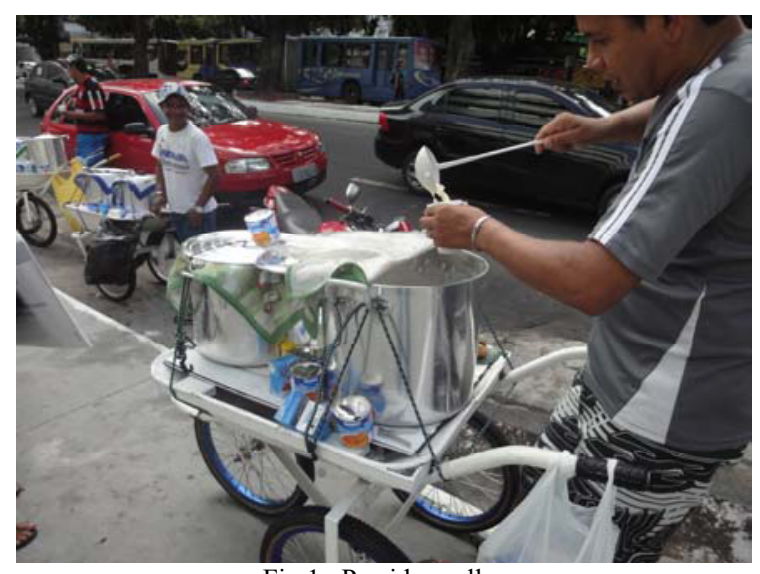

Fig 1 -Porridge seller

Another important problem that deserves attention is related to hygiene. The storage conditions are not appropriate because was observed that the food in question does not have an effective system to isolate it from the external environment, which may favor the proliferation of bacteria and therefore the diseases caused by them. Also, how the porridge is served (the seller does not use gloves or hat hair) is also not in accordance with the standards for food handling [1], as shown in Figure 2.

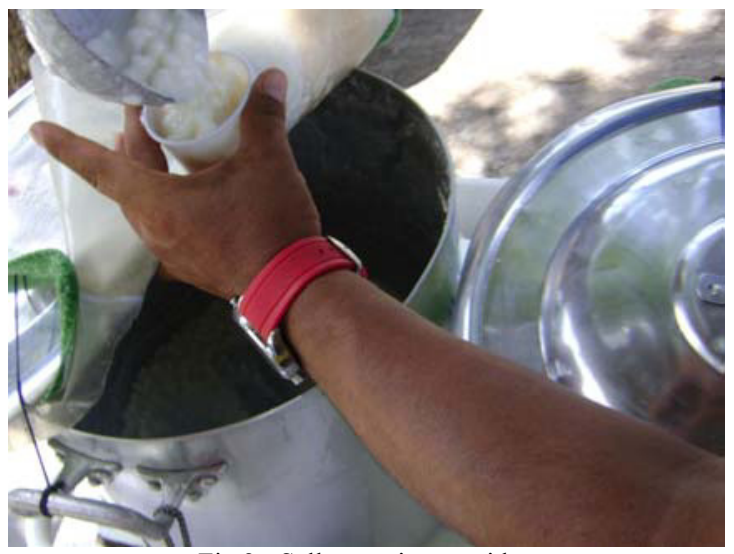

Fig 2 - Seller serving porridge

Analyzing the issues raised previously, to determine measures to the suitability of the job to the seller in order to extinguish or mitigate the constraints caused by the profession.

\subsection{Taxonomic classification}

In light of studies are reported the following problems, according to the taxonomy of Moraes and Mont'Alvão [6], which should be solved:

- Interfacial problems: spinal flexion and rotation of the trunk with excessive overhead due to both inadequate cart layout and arrangement of the containers required for the same lift and transport.

- Movement problems: excess weight that the worker must move during his long working hours daily

- Displacement problems: fatigue and circulatory problems, considering wanderings and the huge distance to make the sale.

- Natural problems: vendors are subject to weather and high levels of noise, since their activities are performed outdoors, in areas of high movement and circulation of vehicles.

- Accident problems: The pans carry hot food and the seller does not have adequate thermal protection to handle them. Night work on public roads, as well as the problems of urban pavement (sidewalk damaged), exposed to the risk of pedestrian accidents and falls. 


\section{Discussion}

\subsection{Ergonomic opinion}

The observed systems possess in common adaptations present in the form of cargo transport, containers, individual protection against bad weather and fire subsystems, hygienization procedures and in the form of food conservation.

Each salesperson conducts adjustments according to their needs and not always do these adjustments live up to the ergonomic safety, comfort and user friendliness requirements.

Disregard for such requirements exposes the workers to stress, diseases and accidents, which range from light to serious, compromising the work's efficiency.

As for the effort of driving the cart, it can inflict low back pains and different problems on the workers' spines. According to Kroemer and Grandjean [5], the handling of cargo usually demands a lot of both static and dynamic effort, enough to qualify as heavy labor. To Iida [4], the weight increase causes a physiological overload in the backbone and lower limb muscles and the contact between cargo and body may induce postural stress, resulting in discomfort, fatigue and pains.

It was observed that the postures taken by the worker when serving the porridge and when moving the cart cause constraints which in long term will become harmful to health. Dul and Weerdmeester [3] state that when the torso leans foward, there is contraction of the back muscles and ligaments to maintain this position, generating great stress in the lower torso, where the pains eventually start. They also state that, the torso torsions cause indesirable tension in the vertebrae, which occur when the intervertebral discs are tensed and the spine articulations and muscles are subjected to assimetric loads, which are harmful.

Because of all this, it is desired to come up with suggestions capable of solving the difficulties encountered daily by these workers, always taking in consideration the existing restrictions, financial above all, so as to effectively apply such improvements.

\subsubsection{Preliminary suggestions for improvement}

After analyzing and considering the restrictions observed, we get the following predictions:
Meet the ergonomic requirements of safety, comfort and ease of use in order to better match work to the worker;

Evaluate transportation systems sales and the like, in order to know the possibilities and subsystems that can be applied to the system in question;

Enter subsystem that offers the driver more comfort by distributing the load evenly and facilitating the transportation, mitigating the human toll caused by overloading the column;

Making systematic use of small breaks during the workday, according to recommendations from the National Institute for Occupational Safety and Health (NIOSH) [7], to relieve muscle fatigue and improve circulation;

Study the possibilities and the best materials for packaging of porridge, in response to problems related to hygiene;

Enter containers for packing and organizing utensils and condiments;

Include procedures for care hygiene during preparation and serving porridge (consider protection for hands and hair);

Workers should use light-colored clothes with reflective strip for work at night.

\section{Conclusion}

This work shows that is possible to improve working conditions of porridge hawker (actor Amazonian culture), based on the study ergonomic problems and procedures. The formulation of the problem is extremely important, because, according to Ackoff apud Moraes and Mont'Alvão [6], successful problem solving requires finding the right solution to the right problem.

It is understood that meeting the ergonomic requirements and the implementation of their contributions, does not always require sizeable investments, since the suggestions are feasible and make possible the maintenance of self-employment a major, inherent in the local culture and can be terminated by the difficulties experienced by this professional segment.

\section{References}

[1] ANVISA; Portaria SVS/MS n ${ }^{\circ} 326,1997$. Available in : http://www.anvisa.gov.br/legis/portarias/326_97.htm, accessed september 20, 2011.

[2] Chaffin, F. B.; Anderson, G. B. J., Martin; B. J. - Biomecânica Ocupacional; Ergo, Belo Horizonte, 2001

[3] Dul, Jan; Weerdmeester, Bernard - Ergonomia Prática; 2.ed. ; Editora Edgard Blücher Ltda; São Paulo, 2004 
[4] IIDA, I. - Ergonomia: Projeto e Produção; Editora Edgard Blücher Ltda; São Paulo, 1990

[5] KROEMER, K.H.E; GRANDJEAN, E. - Manual de Ergonomia: Adaptando o trabalho ao homem; 5.ed.; Bookman; Porto Alegre,2005
[6] MORAES, Ana Maria de; MONT’ALVÃO, Cláudia Ergonomia: conceitos e aplicações; 2AB; Rio de Janeiro, 2009 [7] NIOSH - Work practices guide for manual handling; Washington. DC, US. Department of health and Human Services, Government Office, 1981 